\title{
Social Dominance Orientation: Revisiting the Structure and Function of a Variable Predicting Social and Political Attitudes
}

\section{Citation}

Ho, A. K., J. Sidanius, F. Pratto, S. Levin, L. Thomsen, N. Kteily, and J. Sheehy-Skeffington. 2012. "Social Dominance Orientation: Revisiting the Structure and Function of a Variable Predicting Social and Political Attitudes." Personality and Social Psychology Bulletin 38 (5) (January 3): 583-606. doi:10.1177/0146167211432765.

\section{Published Version}

doi:10.1177/0146167211432765

\section{Permanent link}

http://nrs.harvard.edu/urn-3:HUL.InstRepos:14302021

\section{Terms of Use}

This article was downloaded from Harvard University's DASH repository, and is made available under the terms and conditions applicable to Open Access Policy Articles, as set forth at http:// nrs.harvard.edu/urn-3:HUL.InstRepos:dash.current.terms-of-use\#OAP

\section{Share Your Story}

The Harvard community has made this article openly available.

Please share how this access benefits you. Submit a story.

Accessibility 
2

3

4

5

6

7

8

9

10

11

12

13

14

15

16

17

18

19

20

21

22

23

24

25

26

27

28

29

30

31

32

33

34

35

36

37

38

39

40

41

42

43

44

45

46

47

48

49

50

51

52

53

54

55

56

57

58

59

60
Social Dominance Orientation: Revisiting the Structure and Function of a Variable Predicting

Social and Political Attitudes

Arnold K. Ho and Jim Sidanius

Harvard University

Felicia Pratto

University of Connecticut

Shana Levin

Claremont McKenna College

Lotte Thomsen

Harvard University \& University of Copenhagen

Word Count: 9,108 (including abstract, text, references, and notes)

http://mc.manuscriptcentral.com/pspb 


\begin{abstract}
Social dominance orientation (SDO) is one of the most powerful predictors of intergroup attitudes and behavior. While SDO works well as a unitary construct, some analyses suggest that SDO might consist of two complementary dimensions - SDO-Dominance (SDO-D), or the preference for some groups to dominate others, and SDO-Egalitarianism (SDO-E), a preference for non-egalitarian intergroup relations. Using five samples from the U.S. and Israel, we confirm factor analytic evidence and show predictive validity for both dimensions. In the U.S., SDO-D was theorized and found to be more related to old-fashioned racism, zero-sum competition, and aggressive intergroup phenomena than SDO-E; SDO-E better predicted more subtle legitimizing ideologies, conservatism, and opposition to redistributive social policies. In a contentious hierarchical intergroup context (the Israeli-Palestinian context), SDO-D better predicted both conservatism and aggressive intergroup attitudes. Fundamentally, these analyses begin to establish the existence of complementary psychological orientations underlying the preference for group-based dominance and inequality.

Keywords: SDO, social dominance orientation, group dominance, anti-egalitarianism, hierarchyenhancing and attenuating social policy.
\end{abstract}




\section{Social Dominance Orientation: Revisiting the Structure and Function of a Variable Predicting Social and Political Attitudes}

To "illegal immigrants": "If you commit a crime while you're here, we should hang you and send your body back to where you came from, and your family should pay for it."

- Joyce Kaufman, Tea Party member and Florida radio show host

As this recently publicized statement from Tea Party member and popular Florida radio host Joyce Kaufman illustrates, aggressive discourse surrounding American intergroup politics remains all too common (Wing, 2010). The recent passage of an immigration law in Arizona allowing the police to stop and detain anyone suspected of being an undocumented immigrant shows that aggressive anti-immigration sentiments are not confined to rhetoric. We argue that such aggressive intergroup attitudes and behaviors are an outgrowth of a distinct psychological orientation, which constitutes one component of social dominance orientation (Pratto, Sidanius, Stallworth, \& Malle, 1994).

The overt force and punitiveness prescribed by Kaufman contrast with contemporary apologies opposing affirmative action or limiting international reconciliation. In such rhetoric, other priorities, such as "fairness, meritocracy," or "national security” are deployed rather than overt references to the inferiority of outgroups or the rightness of dominance (e.g., Essex, n.d., Heller, 2010). We argue that such intergroup attitudes and behaviors, although not as openly forceful and hostile, rely on a psychology of group separation and opposition to group equality. This psychological orientation is also an aspect of social dominance orientation. In this article, we explore the implications of both dimensions of social dominance orientation (SDO) for intergroup relations, how ideologies justify inequality, and the psychology of group prejudice. 
Since its introduction two decades ago (see Sidanius, Pratto, Martin, \& Stallworth, 1991, p. 693), SDO has proven to be one of the most versatile and useful constructs for understanding socio-political ideologies, the psychology of prejudice, and intergroup behavior within social psychology. SDO is defined as an individual's preference for group-based hierarchy and inequality, and has been consistently found to undergird an impressive array of intergroup phenomena that serve to either enhance or attenuate group-based hierarchy (Pratto, Stallworth, Sidanius, \& Malle, 1994). For example, SDO has been found to be a powerful predictor of generalized prejudice against, and persecution of, a wide array of denigrated groups such as poor people, Latinos, Asians, foreigners, gays, women, Arabs, Muslims, Blacks, Jews, immigrants, and refugees (e.g., Altemeyer, 1996; Esses, Veenvliet, Hodson \& Mihic, 2008; McFarland \& Adelson, 1996; Sidanius, Pratto \& Mitchell, 1994; Thomsen, Green \& Sidanius, 2008). Further, SDO is related to the endorsement of a broad spectrum of group-relevant social ideologies, including political conservatism, noblesse oblige, just world beliefs, nationalism, patriotism, militarism, internal attributions for poverty, sexism, rape myths, endorsement of the Protestant work ethic, and other consequential hierarchy-enhancing legitimizing ideologies across a range of cultures (Pratto, Liu, Levin, Sidanius, Shih, Bachrach \& Hegarty, 2000; Sidanius \& Pratto, 1999). In addition, SDO is related to attitudes towards group-relevant social policies such as support for wars of aggression, punitive criminal justice policies, the death penalty and torture, and opposition to humanitarian practices, social welfare, and affirmative action (Federico \& Sidanius, 2002; Green, Thomsen, Sidanius, Staerkle, \& Potanina, 2009; Haley \& Sidanius, 2006; Pratto \& Glasford, 2008; Pratto, Stallworth, \& Conway-Lanz, 1998; Sidanius \& Liu, 1992; Sidanius \& Pratto, 1999; Sidanius, Mitchell, Haley, \& Navarrete, 2006). People’s SDO level not only influences endorsement of social policies and ideologies, but also how they live their lives - 
for instance, the kinds of jobs they seek and obtain, the kinds of subjects they choose to study, and how well they perform in these areas (Pratto, Stallworth, Sidanius \& Siers, 1997, for a review see Haley \& Sidanius, 2005).

The generality of SDO is also shown in its ability to predict intergroup attitudes in new situations. For example, in addition to correlating with prejudice toward familiar groups (e.g., ethnic groups), SDO predicts affect towards both minimal groups and novel social policies (e.g., Amiot \& Bouris, 2005; Pratto, Sidanius, Stallworth \& Malle, 1994; Pratto \& Shih, 2000; Reynolds, Turner, Haslam, Ryan, Bizumic, \& Siubasic, 2007; Sidanius, Pratto, \& Mitchell, 1994). SDO has also been shown to predict people’s future intergroup attitudes and behavior across extended periods of time (Kteily, Sidanius, \& Levin, 2011; Sibley, Wilson, \& Duckitt, 2007; Thomsen, Green, Ho, Levin, van Laar, Sinclair, \& Sidanius, 2010). Altogether, empirical evidence from many countries and concerning many different intergroup contexts has shown that the SDO scale is a powerful index of generalized prejudice, group relevant social ideologies, socio-political policy preferences and future career choices (see Pratto, Sidanius, \& Levin, 2006 for a review).

\section{One or Two Dimensions of SDO?}

When the 14-item SDO scale was initially developed, it was found to be uni-dimensional (Pratto et al., 1994, Appendix A, later referred to as the $\mathrm{SDO}_{5}$ scale in Sidanius \& Pratto, 1999). Care was taken to ensure that the item set did not produce response acquiescence (Christie \& Cook, 1958) by including both pro-trait and con-trait SDO items. In addition, work was done to ensure that the SDO scale captures the full expression of the SDO construct, and demonstrates convergent and discriminant validity (e.g., Loevinger, 1957). However, subsequent factor analytic research and experimental research by a number of scholars suggest that the pro-trait 
and con-trait sections of the 16-item $\mathrm{SDO}_{6}$ scale - the most commonly used SDO scale, published in Appendix D of Pratto et al., 1994 - may actually produce two distinct yet strongly related, substantive subdimensions of SDO (e.g., Jost \& Thompson, 2000). One may reflect support for group-based dominance hierarchies (SDO-D) and the other opposition to groupbased equality (SDO-E; see Table 1).

To date, the question of whether $\mathrm{SDO}_{6}$ consists of one dimension or two related dimensions has not been theoretically or empirically resolved. The proposed dimensions are composed entirely of either pro-trait items (SDO-D) or con-trait items (SDO-E). As such, any factor analytic evidence for two dimensions could simply reflect differences in the direction in which items are worded, rather than differences in substance between the two dimensions. Thus, even though our early unpublished analyses of the $\mathrm{SDO}_{6}$ scale showed that two dimensions often emerged, it was not clear whether these dimensions were substantively distinct.

The present paper reviews evidence that the $\mathrm{SDO}_{6}$ scale consists of two related dimensions and, importantly, empirically tests whether the two dimensions differentially predict outcome variables concerning group based dominance and opposition to equality. If our research finds that two subdimensions empirically differentiate among theoretically-relevant measures, this would demonstrate predictive validity for this distinction and suggest the need for newly balanced measures of each dimension. As $\mathrm{SDO}_{6}$ is so widely in use in both experimental and survey research around the world, the results may prove of great theoretical and practical use in understanding prejudice, discrimination, and intergroup relations more broadly.

\section{Dominance and Egalitarianism}

Why might support for group dominance and opposition to group equality reflect two distinct psychological orientations? SDO-D is defined as support for group-based dominance 
hierarchies in which dominant groups actively oppress subordinate groups. It reflects an early definition of SDO as a generalized imperial imperative (Sidanius \& Pratto, 1993). These items specifically tap support for overtly hierarchical intergroup relations (e.g., "Inferior groups should stay in their place”). As such, we hypothesize that SDO-D will be related to phenomena such as support for aggressive intergroup behavior, support of overtly negative intergroup attitudes, support for negative allocations to outgroups, and the perception of group-based competition. These attitudes, behaviors, and cognitions all support dominance hierarchies that involve the active subjugation of some groups by other groups. Indeed, since the SDO-D items encompass the approval of groups that "use force” and "step on other groups," we expect SDO-D to be especially related to support for aggressive behavior in intergroup competition (e.g., ethnic persecution). SDO-D also expresses the belief that some groups are "superior" or "more worthy," and thus should be related to overt or old-fashioned prejudice. For example, Sears, Haley, and Henry (2008) have found that SDO-D correlates with overtly negative feelings toward Blacks among Whites, the belief that Blacks are biologically inferior, and the belief that Blacks are trying to take resources away from other groups. Similarly, given that SDO-D reflects a preoccupation with maintaining the relative power difference between groups, we expect SDO-D to be related to perceptions of zero-sum group competition. Importantly, these aspects of SDO-D should also make it predict the legitimization or justification of extremely hierarchical systems of group-based dominance.

SDO-E is defined as opposition to group-based equality. This includes an aversion to the general principle of equality and to reducing the level of hierarchy. Opposition to equality translates psychologically into support for exclusivity. People who want groups to be unequal wish to exclude certain groups from access to resources that could elevate their social position. 
Therefore, SDO-E should be related to a wide array of subtle, insidious hierarchy-maintaining legitimizing myths, such as symbolic racism or the Protestant work ethic, that imply that it is legitimate for certain groups to be excluded from access to resources. It should further be related to opposition to redistributive social policies because they increase equality, and to policies that would break down group boundaries such as support for affirmative action. Given the nature of SDO-E, it should predict the justification and legitimization of social systems that are socially stratified. However, unlike SDO-D, it should not relate as strongly to support for active domination or extreme subjugation of subordinate groups. Although the two subdimensions should strongly relate to one another, once this overlap is taken into account, they should differentially predict a variety of group-relevant outcomes.

\section{Existing Evidence for the Predictive Validity of Two Dimensions}

Empirical studies from several research groups have shown that SDO-D and SDO-E differentially correspond with group-relevant variables such as endorsement of prejudicial ideologies and political attitudes, and may respond differently to experimental manipulations aimed at promoting fairness between groups. The SDO-E dimension, or some variant of it, accounts for variance in conservatism, opposition to international diplomacy, anti-Black attitudes (not including old-fashioned racism), just world beliefs, and opposition to redistributive social policies (Cohrs, Moschner, Maes, \& Kielmann, 2005; Eagly, Diekman, Johannesen-Schmidt, \& Koenig, 2004; Freeman, Aquino, \& McFerran, 2009; Jost \& Thompson, 2000; Reyna, Henry, Korfmacher, \& Tucker, 2006; Kugler, Cooper, \& Nosek, 2010; Sears et al., 2008; Wakslak, Jost, Tyler, \& Chen, 2007; Yoshimura \& Hardin, 2009).

Some studies have shown that SDO-D differentially accounts for other variables. For example, Eagly et al. (2004) found that SDO-D predicted discrimination against women and 
homosexuals. Because their index of discrimination combined the belief in traditional gender roles with opposition to gay/lesbian rights, it is not clear exactly which aspects of gender and sexual orientation beliefs corresponded to SDO-D. Peña and Sidanius (2002) examined relationships between the two subdimensions and patriotism, or love for one's nation. Contrary to the notion that U.S. patriotism reflects love for an inclusive, egalitarian society, they found that patriotism was more related to SDO-D than to SDO-E. However, Peña and Sidanius used abbreviated SDO-D and SDO-E scales, and did not partial out the effects of SDO-E when examining the effects of SDO-D. Kugler et al. (2010) found that SDO-D uniquely predicted ingroup bias (explicit and implicit), anti-Black bias, opposition to economic redistribution, belief in a just world and symbolic racism among U.S. Whites. However, due to their use of partial rather than semi-partial correlations, we do not know how each SDO dimension, net of the effect of the other dimension, relates to the total variance of each intergroup attitude of interest. ${ }^{1}$ In addition, a few research teams have found that SDO-D appears to have a stronger relationship with RWA than does SDO-E (e.g., Cohrs et al., 2005; Del Prado Silvan-Ferraro \& Bustillos, 2007; Kugler et al., 2010). Freeman et al.’s (2009) analysis of the proposed dimensions was particularly compelling. It showed that the effect of SDO-D on donations to a minority organization among dominants was attenuated by invoking examples of good moral behavior, but the effects of SDO-E were unchanged. They attributed this divergent pattern of moderation to their intuition that the attitudes expressed by SDO-D are less acceptable, especially under circumstances in which people have been primed with moral virtues. As such, SDO-D no longer predicts reduced donations to a minority organization among dominants primed to consider moral virtues. 
Other studies have found no difference in how the two subdimensions predict intergroup attitudes. For example, Guimond, Dambrun, Michinov, and Duarte (2003) found that SDO-D and SDO-E equally predicted prejudice, though their measure of prejudice was a hybrid of positive views of an outgroup and the desire to actively discriminate against an outgroup. Kugler et al. (2010) also found no significant difference between SDO-D and SDO-E’s relationships with implicit and explicit ingroup bias and anti-Black attitudes; both subdimensions of SDO were related to race prejudice among Whites against Blacks and other groups, but the IAT confounds positive ingroup bias and derogatory outgroup bias that may differentially relate to each of the subdimensions of SDO. Finally, others considering the dimensions separately have been primarily interested in the antecedents of SDO (e.g., Foels \& Pappas, 2004) or in interpersonal rather than intergroup competition (e.g., Cozzolino \& Snyder, 2008).

\section{Social Structure May Moderate the Differential Effects of SDO-D and SDO-E}

Due to the rather dramatic decline in explicit and old-fashioned racism within American society (e.g., Schuman, Steeh, Bobo \& Krysan, 1997), Sears and his colleagues have argued that SDO-D is no longer a relevant dimension in intergroup relations and/or socio-political attitudes (see e.g., Sears et al., 2008, p. 83). Sears, Henry, and Kosterman (2000) found that SDO-D does not predict symbolic racism as well as SDO-E, is weakly related to political orientation and racial policy preferences, and does not relate to legitimizing ideologies such as attributions for poverty, crime and structural explanations for racial disadvantage (see also Sears \& Henry, 2005; Sears et al., 2008). However, because most of this research has used highly abbreviated versions of the SDO-D and SDO-E scales, and has not considered the full spectrum of intergroup attitudes and behavior, more research is warranted to test whether SDO-D predicts other intergroup variables in American samples. 
Previous research has also failed to consider the extent to which the differential effects of SDO-D and SDO-E are dependent upon the socio-structural context. In contexts such as the contemporary U.S., where equality is the predominant apology, SDO-E may be more potent. That is, in political-cultural contexts in which people actively consider and debate about equality, people are likely to be primed on this general concept and use it to gauge their views on a variety of social and political issues, especially domestic ones. However, in societies where the predominant apology is about group segregation, difference, the necessity of force, and dominance, SDO-D may be more potent, and may be the lens through which people in such societies, regardless of whether they endorse or reject dominance, view many of their social and political issues.

To test the idea that political cultures can vary as to whether SDO-D or SDO-E is more active, we analyze data from both the U.S. and Israel. Although the U.S. has been engaged in many violent international conflicts in recent decades, nearly all of these conflicts have been outside the U.S. and unrelated to domestic conflicts among American groups (e.g., ethnic groups). Furthermore, despite its international dominance, the U.S.'s internal political rhetoric since the modern civil rights era and women’s rights era is decidedly egalitarian, as many scholars have noted (e.g., Roth, 1994; Thernstrom \& Thernstrom, 1997). Hence, SDO-E may have potency in the U.S., especially when non-overt domestic conflict is under consideration (e.g., ethnic conflict). In contrast, Israel has been and continues to be actively engaged in violent conflict with its Palestinian neighbors. Hence, support for the active and potentially violent subordination of other groups reflected by the SDO-D items may have system-justifying potency in Israel, especially when overt group boundaries and conflict with Palestinians are under consideration. Of course, our theoretical reasoning concerning how social structure may 
moderate the differential effects of SDO-D and SDO-E should extend to cultures other than the U.S. and Israel, but as an initial test of this reasoning, we selected these two countries due to the contrast in their predominant political rhetoric. In sum, we expect that in hierarchical intergroup contexts such as the Israeli-Palestinian conflict, SDO-D will be positively related to support for hierarchy-enhancing legitimizing ideologies that both reinforce group-based dominance (e.g., nationalism) and maintain the unequal status quo (e.g., political conservatism).

\section{The Present Research}

Although previous studies have examined the proposed dimensions of SDO separately, more evidence is needed to establish the unique predictive validity of each dimension, net of the effects of the other dimension. Furthermore, the operationalizations of these dimensions have been inconsistent across studies, with some researchers using a shortened scale and others augmenting $\mathrm{SDO}_{6}$ items with novel items, including items that conflate group-based egalitarianism with interpersonal egalitarianism. Finally, previous findings have been inconsistent, partly because of the operationalization of variables presumed to be related to SDO. The present study aims to fill these lacunae. Using data from four American samples and one Israeli sample, we test five hypotheses:

1) In all samples, the $\mathrm{SDO}_{6}$ scale should be composed of two subdimensions, reflecting the preference for group-based dominance hierarchies (SDO-D) and opposition to egalitarian intergroup relations (SDO-E).

2) In all samples, the $\mathrm{SDO}_{6}$ subdimensions should be strongly correlated. Although we hypothesize that each dimension should be uniquely related to a preference for qualitatively different relations between groups, both dimensions support group-based social stratification and as such should overlap considerably. 
3) In all samples, SDO-D will be positively related to perceptions that intergroup conflict is zero-sum, aggressive intergroup attitudes and behavior (e.g., immigrant persecution), and overt, or "old-fashioned” prejudice.

4) In contested hierarchical intergroup contexts, such as the Israeli-Palestinian context, SDO-D should be positively related both to support for ideologies that reinforce group dominance (e.g., nationalism) and to support for ideologies that reinforce unequal status relations with subordinate groups (e.g., political conservatism).

5) In less contested hierarchical intergroup contexts, such as the Ashkenazi-Mizrachi Jewish ethnic context in Israel and the ethnic context in the United States, SDO-E should be related to support for insidious hierarchy-enhancing legitimizing ideologies such as system legitimacy beliefs, negative affect toward subordinate groups, and opposition to redistributive social policies.

We test these hypotheses using the full 16-item $\mathrm{SDO}_{6}$ scale in five large surveys administered in the U.S. and Israel. As large surveys do not typically use the full SDO scale, the presence of the full scale in these samples, including one general population survey, represents a rare opportunity to test these hypotheses using large datasets. In the American samples, only the responses of Whites were analyzed, as the responses of non-Whites to some of our criterion variables should relate differentially to SDO. Similarly, in the Israeli sample, only the responses of Ashkenazi Jews, the dominant Jewish ethnic group, were analyzed.

\section{Method}

\section{Participants}

Four American samples. In all four samples, we only analyzed data from respondents who indicated that the United States was their native country. Our data for Sample 1 were drawn 
from a survey of University of California, Los Angeles (UCLA) undergraduates given in 1993. The sample consisted of 186 White participants (51.6\% females; one respondent did not report gender; average age $=21.40, S D=3.76$ ). Respondents were offered the chance to win one of four $\$ 50$ prizes.

Samples 2 and 3 were also drawn from a university, but in a different region in the United States. These samples consisted of participants from the psychology department participant pool at Harvard University. Participants completed the survey for course credit and/or eligibility for studies in the participant pool. The study pool consisted of university students, staff, and members of the local community. Sample 2 completed the survey in 2007. The sample consisted of 491 Whites (66.7\% female). A few participants ( $0.4 \%$ of the sample) indicated they were younger than 18 years old, $45.8 \%$ were between 18-21, 15.9\% were between $22-25,12.6 \%$ were between 26-30, and the remainder were above 30. Sample 3 completed the survey in 2009. The sample consisted of 1,711 Whites after excluding those who also participated in Sample 2. The sample was $76.6 \%$ female. A few participants ( $0.2 \%$ of the sample) were under $18,24.7 \%$ were $18-21$ years old, $15.1 \%$ were $22-25,17.1 \%$ were $26-30,12.4 \%$ were $31-35$, and the remainder were over 36 .

Sample 4 was from the 1996 Los Angeles County Social Survey, which is a large, omnibus survey of Los Angeles County residents recruited using a probability sampling procedure. The survey was administered by telephone using a random digit dialing procedure. This sample included 182 Whites (52.7\% female), and the average age was $47.12(S D=15.61)$.

Israeli sample. Our data for Sample 5 were collected from undergraduate students surveyed in 1994 at Hebrew University, Bar-Ilan University, and the Technion. The sample consisted of 220 Ashkenazi Jews, who are the dominant Jewish ethnic group in Israel. Of this 
sample, 59.1\% were female, and the average age was $23.84(S D=2.98)$. The survey was administered in Hebrew. The survey was translated into Hebrew and then back-translated into English to ensure equivalence of meaning across the original and back-translated surveys.

\section{Measures}

SDO. The full 16-item $\mathrm{SDO}_{6}$ scale was used in all five samples (see Table 1 for items). In Samples 1-3, all items were answered on a 7-point scale, with 1 = Strongly disagree/disapprove and 7 = Strongly agree/approve. In Sample 4, a 4-point scale was used, ranging from 1 = Strongly disagree to $4=$ Strongly agree. Sample 5 used a 7 -point scale, with 1 $=$ Do not agree at all and $7=$ Strongly agree. Alpha reliabilities are reported below, after we use factor analyses to show what items constitute the two dimensions.

\section{Intergroup attitudes hypothesized to be more strongly related to SDO-D. We} expected old-fashioned prejudice, zero-sum competition, and aggressive intergroup attitudes to be more strongly related to SDO-D than to SDO-E (see Appendix 1 for items and scale reliabilities for all samples). “Old-fashioned” prejudice alleges that Blacks and Latinos in the American context and Mizrachi Jews in the Israeli context are intellectually challenged, have a poor work ethic, and are generally “inferior.” It was measured in Samples 1, 2, 3, and 5. Zerosum competition addresses the notion that a gain for certain groups entails a loss for other groups. It was measured in Samples 1, 4, and 5. Various aggressive intergroup attitudes were measured. Nationalism (measured in Samples 1 and 5) represents a particularly aggressive assertion of one's country as superior, reflecting the desire to dominate other countries. Beliefs about immigrant persecution were assessed in Samples 2 and 3 by a variation of Altemeyer's Posse Scale, an instrument measuring one’s willingness to participate in persecution of and violence against immigrants (Altemeyer, 1996; Thomsen et al., 2008). Sample 5 included some 
variables that pertained directly to the longstanding Israeli-Palestinian conflict, including the denial of Palestinians' right to land, belief in the Jewish right over all of Israel, and the belief that ceding land to Palestinians is a threat to security. Sample 5 also contained a variable indexing support for war as a means of maintaining superiority. Importantly, sample 5 uniquely allows us to test whether variables that we hypothesize are more related to SDO-E than SDO-D in the U.S. and similar societies (i.e., outgroup affect, political conservatism) might be strongly related to SDO-D in the relatively hierarchical Israeli-Palestinian context. Such variables included affect toward Palestinians and right-wing political identification.

Intergroup attitudes hypothesized to be more strongly related to SDO-E. We expected political conservatism (in the U.S.), system justification/legitimacy beliefs, opposition to affirmative action, the Protestant work ethic, the belief that college admissions are fair, opposition to various redistributive racial/social policies, symbolic racism, and affect toward the Mizrachim (in Israel) to be more strongly related to SDO-E than to SDO-D (see Appendix 1 for items and reliability statistics). Conservatism was measured through political party affiliation and self-placement on social and economic conservatism scales. It was assessed in Samples 1, 2, 3, and 4. System justification/legitimacy beliefs, measured in Samples 1, 2, and 5, represent the idea that one gets what one deserves, and the social system is fair and just. Opposition to affirmative action was measured in Samples 1, 2, and 4. Similar to system legitimacy beliefs, the Protestant work ethic reflects the view that one will be rewarded for what one works for. It was measured in Samples 1 and 4. Samples 2 and 3 also asked about the legitimacy of admissions to an elite university (Harvard), which can be interpreted as a system legitimacy belief. Opposition to various redistributive racial/social policies was measured in Samples 1, 2, 3, and 5. Sample 4 was unique in assessing support for symbolic racism, which contrasts with the "old-fashioned" 
racism believed to be related to SDO-D. Finally, we believed affect toward Mizrachi Jews (the lower status Jewish ethnic group) would be more strongly related to SDO-E. Negative affect is a core component of symbolic racism, which we generally believe to be more strongly related to SDO-E. Note, however, that this prediction stands in contrast to our prediction that SDO-D will relate more strongly to affect toward Palestinians. Given the long-standing and continuing Israeli hostility towards Palestinians, we reasoned that affect toward Palestinians would be predicted substantially more by support for active group dominance than by opposition to group equality.

\section{Results}

Our first goal was to test whether in fact a two-factor model of the $16 \mathrm{SDO}_{6}$ items fits the data better than a one-factor model. We conducted confirmatory factor analyses with two correlated latent dimensions representing SDO-D and SDO-E. Each dimension was represented by three parcels, which included the eight items expected to represent the dimension (see Table 1). Parcel 1 consisted of the mean of items 1-3 under SDO-D in Table 1, Parcel 2 consisted of the mean of items 4-6 under SDO-D, and Parcel 3 was the mean of items 7-8 under SDO-D. Parcels 4, 5, and 6 were the means of items 1-3, 4-6, and 7-8 under SDO-E, respectively. The use of item parcels rather than individual items has been shown to reduce the random error of manifest indicators. That is, the reliability of our indicators is improved because forming composites (parcels) will take into account the random error associated with any one item. In Sample 1, the two-factor model yielded an excellent fit with just two modifications $\left(\chi^{2} / \mathrm{df}\right.$ ratio $=$ $1.00, \mathrm{RMSEA}=.00, \mathrm{CFI}=1.00$ ), whereas the one-factor model yielded a relatively poor fit even after two modifications $\left(\chi^{2} / \mathrm{df}\right.$ ratio $=5.88$, RMSEA $\left.=.17, \mathrm{CFI}=.95\right) .{ }^{2}$ The chi-square difference 
test showed a significant deterioration of model fit in the one-factor model $\left(\chi_{\text {diff }}^{2}=35.15\right.$, $\mathrm{df}=1$, $p<.001$ ). Identical analyses in Samples 2-5 yielded similar results (see Table 2). ${ }^{3}$

Having replicated previous findings demonstrating that a two-factor model fits the data better than a unidimensional model, we computed the reliabilities for the two SDO subscales. The SDO-D dimension was found to be highly reliable in all five samples: Sample $1, \alpha=.89$; Sample 2, $\alpha=.91$; Sample 3, $\alpha=.92$; Sample 4, $\alpha=.82$; Sample 5, $\alpha=.81$. The SDO-E dimension was reliable as well: Sample 1, $\alpha=.88$; Sample 2, $\alpha=.90$; Sample 3, $\alpha=.91$; Sample 4, $\alpha=.80$; Sample 5, $\alpha=.79$. These dimensions are used in all subsequent analyses.

To test Hypothesis 2, concerning the relationship between SDO-D and SDO-E, we computed the Pearson correlation coefficients for the relationship between the two dimensions. In Sample 1, the correlation between the two dimensions was .53 $(p<.001)$. In Sample 2, the correlation was .49 $(p<.001)$. In Sample 3, the correlation was .44 $(p<.001)$. In Sample 4, the correlation was .36 $(p<.001)$. Finally, in sample 5, the correlation was .49 $(p<.001)$.

Hypothesis 3 predicted that SDO-D would correlate more strongly with endorsing intergroup aggression, subordinate group inferiority, zero-sum competition between groups, and overt domination than would SDO-E. To test this hypothesis, we regressed each of the intergroup attitudes thought to be related to this dimension on SDO-D and SDO-E in a multiple regression analysis, and obtained semi-partial correlations. If our hypothesis is confirmed, the semi-partial correlation between SDO-D and each criterion should be stronger than each criterion's relationship to SDO-E. To test this, we used Malgady’s test for comparing two dependent semipartial correlations (Hittner, Finger, Mancuso, \& Silver, 1995). We used one-tailed tests given our a priori predictions concerning which dimension should more strongly relate to the criterion 
variables we examine. Given the large number of analyses involved, we refer the reader to Table 3 rather than present all statistics in the text, where we describe the findings. ${ }^{4}$

Old-fashioned prejudice was measured in Samples 1, 2, 3, and 5, and predicted significantly by SDO-D in all four samples (see Table 3). Furthermore, it was significantly more strongly related to SDO-D than to SDO-E in Samples 2 and 3, marginally significantly more related to SDO-D than to SDO-E in Sample 1, and more strongly related to SDO-D, though not significantly so, in Sample 5.

Perceptions of zero-sum competition vis-à-vis a subordinate ethnic group was assessed in Samples 1, 4, and 5, and as expected, was significantly predicted by SDO-D in all three samples and significantly more strongly predicted by SDO-D than by SDO-E in all samples.

We also assessed attitudes toward aggressive intergroup behavior (i.e., nationalism and immigrant persecution). Nationalism was related to SDO-D in the way we expected in Sample 5 - i.e., significantly related to SDO-D and significantly more related to SDO-D than SDO-E - but was only marginally significantly related to SDO-D in Sample 1. Interestingly, nationalism was also significantly positively related to SDO-E in Sample 1, and significantly negatively related to SDO-E in Sample 5. In both Samples 2 and 3, beliefs about immigrant persecution were significantly related to SDO-D and more strongly related to this dimension than to SDO-E.

Finally, Sample 5 provided the greatest number of unique variables to test the differential predictive power of SDO-D. The semi-partial correlations indicated that SDO-D significantly predicted the denial of a Palestinian right to land, the belief that Jews have a right to all of Israel, the belief that ceding land to Palestinians threatens Israeli security, and support for war to maintain national superiority. SDO-D predicted all of these variables significantly better than SDO-E did. 
In support of Hypothesis 4 - the prediction that SDO-D would be related to outcomes that justify the existing hierarchy in contexts where the hierarchy is severe and highly contested SDO-D also significantly predicted affect toward Palestinians and right-wing political identification in Israel, and these variables were better predicted by SDO-D than by SDO-E. Whereas we hypothesized that outgroup affect and political conservatism would be more related to SDO-E in a less hierarchical context, it appears that support for right-wing political establishments and negative affect toward subordinate groups are strongly related to SDO-D when power relations are more contested and hierarchical.

Our next test, Hypothesis 5, predicted that SDO-E would correlate more strongly with endorsement of subtle legitimizing myths (e.g., symbolic racism), support for the status quo (e.g., system legitimacy beliefs), and opposition to redistributive social policies. We also predicted that SDO-E would relate more strongly to political conservatism in the United States. We followed the same regression procedure used to test Hypothesis 3, regressing each of these variables on SDO-D and SDO-E, and again examined whether the semi-partial correlations were significantly different (through one-tailed tests; See Table 4).

We measured political conservatism in all four American samples (Samples 1-4), and in every case, found that it was significantly predicted by SDO-E and significantly more strongly related to SDO-E than SDO-D.

System justification/legitimacy beliefs were assessed in the first two American samples (Sample 1 and 2), and in both cases, it was predicted significantly by SDO-E and more strongly by SDO-E than SDO-D. We also measured system justification in the Israeli context. As this measure assessed beliefs in justice for the Jewish ethnic groups in Israel (a less contested hierarchical context similar to race relations in the US), we expected SDO-E to be related to 
system justification. Again, SDO-E was indeed related to system justification in the Israeli context, but not more strongly than it was related to SDO-D. Consistent with our expectations, we found that perceptions of equal opportunity for the Jewish ethnic groups in Israel were predicted significantly by SDO-E in Sample 5, and were more positively related to this dimension than to SDO-D.

Turning to affirmative action in the US, as we expected, opposition to this policy was predicted significantly by SDO-E in all three samples in which it was measured (Samples 1, 2, and 4), and significantly more related to this dimension than to SDO-D. The Protestant work ethic in the US was similarly significantly related to SDO-E in Samples 1 and 4, and significantly more related to this dimension than SDO-D in Sample 1.

We also expected that the belief that the admissions process to Harvard University is fair would be positively related to SDO-E and more positively related to SDO-E than to D, and found in Samples 2 and 3 that this was indeed the case.

Opposition to various redistributive social policies - i.e., opposition to legally enforced racial policy and opposition to social welfare in Sample 1, opposition to redistributive social policy and opposition to civil rights activism in Samples 2 and 3, and opposition to income redistribution (between Jewish ethnic groups in Israel) in Sample 5 - was found to be significantly predicted by SDO-E in all seven of these cases and was significantly more related to SDO-E than to SDO-D in all cases except with respect to civil rights activism in Sample 2, where the magnitude of the relationship with SDO-E was still stronger.

Symbolic racism was measured in Sample 4, and as expected, it was significantly related to SDO-E and marginally significantly more strongly related to SDO-E than to SDO-D. 
Finally, in Sample 5, we found that affect toward the Mizrachi Jews was significantly predicted by SDO-E but not significantly more strongly predicted by SDO-E than by SDO-D. Relationships with affect toward Palestinians were different. Although negative affect is a component of symbolic racism, and thus generally expected to be better predicted by SDO-E, when an outgroup that is engaged in a bitter conflict with the dominant group (Palestinians vis-àvis the dominant Jewish group in Israel) is considered, it is better predicted by SDO-D than by SDO-E.

\section{Discussion}

The present research examined whether the $\mathrm{SDO}_{6}$ scale consists of two distinct, substantive subdimensions - support for group-based domination and opposition to group-based equality. We tested both the factor analytic structure of the SDO items and whether each subdimension of SDO differentially predicts criterion variables in five samples. Results supported all of our hypotheses. Specifically, in all five samples, a two-factor solution accounted for the intercorrelations among the $16 \mathrm{SDO}_{6}$ items better than a one-factor solution, confirming Hypothesis 1 that SDO is composed of two subdimensions. Notably, and confirming Hypothesis 2, SDO-E and SDO-D were both very strongly correlated in every sample. Our substantive hypotheses examined the kinds of intergroup attitudes that should be more strongly related to SDO-D or to SDO-E. Confirming Hypothesis 3 - that SDO-D especially relates to the active and forceful subjugation of outgroups - endorsing immigrant persecution, old-fashioned racism, perceived zero-sum competition, and support for war were all significantly predicted by SDO-D beyond the effects of SDO-E in the U.S. and in Israel. Furthermore, consistent with the hypothesis that SDO-D would also predict system legitimizing/justifying ideologies (e.g., conservatism) in extremely hierarchical and highly conflictual intergroup contexts, we found that 
in the context of the Israeli-Palestinian conflict, high status Israelis exhibited a relationship between SDO-D on the one hand, and political conservatism and negative affect toward Palestinians on the other hand. Hypothesis 5 proposed that SDO-E especially relates to less confrontational hierarchy-enhancing ideologies that legitimize relatively egalitarian but still socially stratified systems. Confirming this, we found that for the variables we thought would be predicted by SDO-E, namely, subtle hierarchy-enhancing legitimizing ideologies and hierarchyattenuating social policies, most were predicted significantly by SDO-E, controlling for the effects of SDO-D, and were more strongly predicted by SDO-E than by SDO-D.

Given these findings, it appears safe to conclude that there are two related but distinct aspects of SDO, and these aspects predict qualitatively different intergroup phenomena. The point of greatest convergence between us and two other research teams who have been examining the structure of SDO, namely Jost and Thompson (2000) and Kugler et al. (2010) lies in our collective views on what SDO-E should relate to. That is, all three research teams argue for and find support for the relationship between SDO-E and hierarchy-attenuating social policies (e.g., affirmative action opposition) and political conservatism in the United States. The replication of these findings by independent research teams using different operationalizations of criterion measures provides confidence that SDO-E corresponds to non-inclusive and nonegalitarian preferences regarding intergroup relations.

Despite this similarity in our mutual understanding of SDO-E, our interpretation differs somewhat from the system-justification approach of Jost and Thompson (2000) and Kugler et al. (2010) in two important ways. First, we do not believe that the concept of system-justification necessarily always invokes sentiments expressed by SDO-E. For example, in Sample 5, support for right-wing political beliefs, a typical measure of endorsement of the status quo, was more 
strongly related to SDO-D than to SDO-E. We argue that in hierarchical societies engaged in violent intergroup conflicts, legitimizing the existing social structure may be more strongly related to SDO-D than to SDO-E. In other words, the relational orientations that motivate system justification hinge crucially upon the kinds of relationships the system entails. When the system entails contested dominance relations, such as the Israeli-Palestinian conflict, support for the hierarchical status quo may be motivated more by support for group-based dominance than by opposition to group-based equality.

A second way in which our perspective differs from that of others is that in contrast to Kugler et al. (2010), we do not see SDO-D as the prejudice dimension. Rather, we believe that different types of prejudice are related to the two SDO dimensions. What is often called oldfashioned prejudice, that is, the belief in outgroup inferiority, should serve to legitimize groupbased dominance and thus should be related to SDO-D. However, prejudice that is not dressed up in notions of outgroup inferiority, but in reference to other values that nonetheless have the consequence of demeaning outgroups, like symbolic racism, should be more related to SDO-E. This is because symbolic racism is based upon the belief that minority group members violate traditional values (i.e., the Protestant work ethic), which constitutes a legitimizing ideology that supports inequality, but not necessarily outright dominance (e.g., Reyna et al., 2009). Our data confirm the conceptual distinction between "old-fashioned” and "modern” prejudice and show that modern prejudice is still motivated by support for group inequality. Furthermore, we emphasize that SDO-E is about group-based inequality. While it should share variance with prior operationalizations of anti-egalitarianism (e.g., Katz \& Hass, 1988), group-based antiegalitarianism should be distinguished from beliefs about interpersonal equality. 
Contrary to the conclusions of Sears et al. (2008), the present evidence shows that the SDO-D dimension is far from being socio-politically inert, even in the U.S. Rather, we found that it is substantially related to a number of socio-political phenomena such as perception of zero-sum group competition, nationalism, old-fashioned racism, and the willingness to participate in the persecution of immigrants. In the Israeli sample, SDO-D was further related to support for war, affect toward Palestinians, and various forms of opposition to making concessions to Palestinians. Indeed, we found that SDO-D was a better predictor than SDO-E was for aggressive intergroup behaviors, perceptions of zero-sum intergroup competition, and old-fashioned racism. While SDO-D may not predict more subtle acts of intergroup bias, like support for less extreme hierarchy-enhancing ideologies, or opposition to hierarchy-attenuating social policies, we have demonstrated that it is useful in understanding more extraordinary, potentially costly intergroup conflicts.

Throughout our analysis of the four American datasets, we were able to find more variables we thought would be related to SDO-E than SDO-D. We do not believe this was by chance. Many theorists in the field of intergroup relations have argued that persuasion, or ideological control, is the preferred means of social control, compared to the use of naked force, in maintaining group-based hierarchies (e.g., Jackman, 1994; Sidanius \& Pratto, 1999; Tyler, 2006). As such, the relatively mundane aspects of intergroup conflict that are best predicted by SDO-E should be more common than the relatively extreme intergroup behaviors and beliefs that emerge from SDO-D.

Importantly, we note that in many instances, it may still be best to use the full SDO scale. Many forms of bias might naturally mix elements of both dimensions of SDO. For example, perceiving mixed-race individuals as belonging more to their subordinate parent group (i.e., 
according to a rule of hypodescent) might entail the belief that the subordinate parent group is inferior, but at the same time constitute a relatively subtle means of maintaining status boundaries (Ho, Sidanius, Levin, \& Banaji, 2011). In such cases, separating the SDO scale will not prove more useful than using the full scale. We recommend that future tests of the separate dimensions be guided by the theoretical distinction we make between the underlying psychological processes of support for group-based dominance and unequal group relations. For example, social dominance theory argues that the SDO scale is a good measuring stick for testing the function of legitimizing myths, in particular whether they are hierarchy-enhancing or hierarchy-attenuating. Along these lines, examining whether a legitimizing myth is more related to SDO-D or SDO-E may help ascertain whether the myth is intended to support dominance and oppression involving the use of force, or intended to uphold inequality in less overt ways. For example, the finding that old-fashioned racism is more related to SDO-D and symbolic racism is more related to SDO-E suggests that old-fashioned racism might justify forceful forms of group oppression such as slavery or apartheid, whereas symbolic racism might lead one to oppose equality for all groups, but not support the use of force to dominate subordinate groups.

We view both dimensions of SDO as primarily supporting generalized group-based hierarchy rather than ingroup dominance (Pratto et al., 2006), even if there are qualitative differences in the character of the hierarchy the two dimensions support. However, at present, a few items in the SDO-D dimension (e.g., "In getting what your group wants, it is sometimes necessary to use force against other groups”) may be interpreted as support for ingroup dominance. Future measures of SDO should remove this potential confound.

Social dominance theorists have long argued and demonstrated that individual differences in the desire for group-based hierarchy have serious consequences for the ways in which 
individuals engage in intergroup relations. The new analyses presented in this study demonstrate that depending on the outcome and the socio-structural context, one component of SDO might be more consequential than the other. These findings should help us understand more precisely the underpinnings of intergroup conflict, whether it occurs on the battlefield or in the voting booth. We hope that continued analysis of SDO's structure and function, and the further development of its measurement, will shed more light on what motivates various manifestations of intergroup conflict. 


\section{References}

Altemeyer, B. (1996). The authoritarian specter. Cambridge, MA US: Harvard University Press. Amiot, C., \& Bourhis, R. (2005). Ideological beliefs as determinants of discrimination in positive and negative outcome distributions. European Journal of Social Psychology, 35, 581598.

Christie, R. \& Cook, P. (1958). A guide to published literature relating to the authoritarian personality through 1956. Journal of Psychology, 45, 1717-1799.

Cohrs, Moschner, Maes, \& Kielmann (2005). The motivational bases of right-wing authoritarianism and social dominance orientation: Relations to values and attitudes in the aftermath of September 11, 2001. Personality and Social Psychology Bulletin, 31, 1425-1434.

Cozzolino, P., \& Snyder, M. (2008). Good times, bad times: How personal disadvantage moderates the relationship between social dominance and efforts to win. Personality and Social Psychology Bulletin, 34, 1420-1433.

Del Prado Silván-Ferrero, M., \& Bustillos, A. (2007). Adaptación de la escala de orientación a la dominancia social al castellano: Validación de la dominancia grupal y la oposición a la igualdad como factores subyacentes. Revista de Psicología Social, 22, 3-15.

Eagly, A. H., Diekman, A. B., Johannesen-Schmidt, M. C., \& Koenig, A. G. (2004). Gender Gaps in Sociopolitical Attitudes: A Social Psychological Analysis. Journal of Personality and Social Psychology, 87, 796-816.

Esses, V., Evenly, S., Hudson, G., \& Mimic, L. (2008). Justice, morality, and the dehumanization of refugees. Social Justice Research, 21, 4-25. 
Essex, T. R. (n.d.) Real reasons to oppose affirmative action. National Leadership Network of Conservative African-Americans. Retrieved Jan 4, 2011 from http://www.nationalcenter.org/P21NVEssexAAction104.html

Federico, C. M., \& Sidanius, J. (2002). Racism, ideology, and affirmative action, revisited: The antecedents and consequences of 'principled objections' to affirmative action. Journal of Personality and Social Psychology 82, 488-502.

Foels, R., \& Pappas, C. (2004). Learning and unlearning the myths we are taught: Gender and social dominance orientation. Sex Roles, 50, 743-757.

Freeman, D., Aquino, K., \& McFerran, B. (2009). Overcoming beneficiary race as an impediment to charitable donations: Social dominance orientation, the experience of moral elevation, and donation behavior. Personality and Social Psychology Bulletin, 35, 72-84.

Green, E., Thomsen, L., Sidanius, J., Staerkle, C., \& Potanina, P. (2009). Reactions to crime as a hierarchy regulating strategy: The moderating role of social dominance orientation. Social Justice Research, 22, 416-436.

Guimond, S., Dambrun, M., Michinov, N., \& Duarte, S. (2003). Does social dominance generate prejudice? Integrating individual and contextual determinants of intergroup cognitions. Journal of Personality and Social Psychology, 84, 697-721.

Haley, H., \& Sidanius, J.(2005). Person-organization congruence and the maintenance of groupbased social hierarchy: A social dominance perspective Group processes \& intergroup relations, 8, 187-203.

(2006). The positive and negative framing of affirmative action: A group dominance perspective. Personality and Social Psychology Bulletin, 32, 656-668. 
Heller, J. (2010, Nov. 11). Clinton offers Netanyahu security pledge on peace talks. Retrieved Jan. 4, 2011 from http://www.reuters.com/article/idUSTRE6AA57F20101111

Hittner, J.B., Finger, M.S., Mancuso, J.P., \& Silver, N.C. (1995). AMicrosoft FORTRAN 77 program for contrasting part correlations and related statistics. Educational and Psychological Measurement, 55, 777-784.

Ho, A. K., Sidanius, J., Levin, D. T., \& Banaji, M. R. (2011). Evidence for hypodescent and racial hierarchy in the categorization and perception of biracial individuals. Journal of Personality and Social Psychology.

Jackman, M. (1994). The velvet glove: paternalism and conflict in gender, class, and race relations. Berkeley, CA: University of California Press.

Jost, J.T., \& Thompson, E.P. (2000). Group-based dominance and opposition to equality as independent predictors of self-esteem, ethnocentrism, and social policy attitudes among African Americans and European Americans. Journal of Experimental Social Psychology, 36, 209-232.

Katz, I., \& Hass, R. (1988). Racial ambivalence and American value conflict: Correlational and priming studies of dual cognitive structures. Journal of Personality and Social Psychology, 55(6), 893-905.

Kteily, N., Sidanius, J. \& Levin, S, (2011). Social dominance orientation: Cause or 'mere effect'? Evidence for SDO as a causal predictor of prejudice and discrimination against ethnic and racial outgroups. Journal of Experimental Social Psychology.

Kugler, M. B., Cooper, J., \& Nosek, B. A. (2010). Group-based dominance and opposition to equality correspond to different psychological motives. Social Justice Research, 23, 117155. 
Loevinger, J. (1957). Objective tests as instrument of psychological theory. Psychological Reports, Monograph Supplement 9.

McFarland, S. \& Adelson, S. (1996, July). An Omnibus Study of Personality and Prejudice. Paper presented at the meeting of the International Society of Political Psychology, Vancouver, Canada.

Peña, Y., \& Sidanius, J. (2002). U.S. patriotism and ideologies of group dominance: A tale of asymmetry. The Journal of Social Psychology, 142, 782-790.

Pratto, F., \& Glasford, D. (2008). Ethnocentrism and the value of a human life. Journal of Personality and Social Psychology, 95, 1411-1428.

Pratto, F., Liu, J. H., Levin, S., Sidanius, J., Shih, M., Bachrach, H. \& Hegarty, P. (2000). Social dominance orientation and the legitimization of inequality across cultures. Journal of Cross-Cultural Psychology, 31, 369-409.

Pratto, F., \& Shih, M. (2000). Social dominance orientation and group context in implicit group prejudice. Psychological Science, 11(6), 515-518.

Pratto, F., Sidanius, J., \& Levin, S. (2006). Social dominance theory and the dynamics of intergroup relations: Taking stock and looking forward. European Review of Social Psychology, 17, 271-320.

Pratto, F., Sidanius, J., Stallworth, L.M., \& Malle, B.F. (1994). Social dominance orientation: A personality variable predicting social and political attitudes. Journal of Personality and Social Psychology, 67, 741-763.

Pratto, F., Stallworth, L., \& Conway-Lanz, S. (1998). Social dominance orientation and the ideological legitimization of social policy. Journal of Applied Social Psychology, 28, 1853-1875. 
Reynolds, K., Turner, J., Haslam, S., Ryan, M., Bizumic, B., \& Subasic, E. (2007). Does personality explain in-group identification and discrimination? Evidence from the minimal group paradigm. British Journal of Social Psychology, 46, 517-539.

Reyna, C., Henry, P., Korfmacher, W., \& Tucker, A. (2006). Examining the principles in principled conservatism: The role of responsibility stereotypes as cues for deservingness in racial policy decisions. Journal of Personality and Social Psychology, 90, 109-128.

Roth, B. M. (1994). Prescription for failure: Race relations in the age of social science. New Brunswick, NJ: Transaction Publishers.

Schuman, H., Steeh, C., Bobo, L., \& Krysan, M. (1997). Racial attitudes in America: Trends and interpretations (rev. ed.). Cambridge, MA US: Harvard University Press.

Sears, D. O., Haley, H., \& Henry, P. J. (2008). Cultural diversity and sociopolitical attitudes at college entry. In J. Sidanius, S. Levin, C. van Laar, \& D. O. Sears (Eds.), The Diversity Challenge (pp. 65-99). New York: Russell Sage Foundation.

Sears, D., \& Henry, P. (2005). Over thirty years later: A contemporary look at symbolic racism. Advances in experimental social psychology, Vol. 37 (pp. 95-150). San Diego, CA US: Elsevier Academic Press.

Sears, D. O., Henry, P. J., \& Kosterman, R. (2000). Egalitarian values and contemporary racial politics. In D. O. Sears, J. Sidanius, \& L. D. Bobo (Eds.), Racialized Politics. Chicago: University of Chicago Press.

Sibley, C., Wilson, M., \& Duckitt, J. (2007). Effects of dangerous and competitive worldviews on Right-Wing Authoritarianism and Social Dominance Orientation over a five-month period. Political Psychology, 28, 357-371.

Sidanius, J., Levin, S., \& Pratto, F. (1996). Consensual social dominance orientation and 
its correlates within the hierarchical structure of American society. International Journal of Intercultural Relations, 20, 385 - 408.

Sidanius, J. \& Liu, J. (1992). Racism, Support for the Persian Gulf War, and the Police Beating of Rodney King: A Social Dominance Perspective. Journal of Social Psychology, 132, $685-700$.

Sidanius, J., Mitchell, M., Haley, H., \& Navarrete, C. D. (2006). Support for harsh criminal sanctions and criminal justice beliefs: A social dominance perspective. Social Justice Research, 19, 433-449.

Sidanius, J. \& Pratto, F. (1993). The inevitability of oppression and the dynamics of social dominance. In P. Sniderman \& P. Tetlock (Eds.), Prejudice, Politics, and the American Dilemma. Stanford University Press, pp. 173-211.

Sidanius, J., \& Pratto, F. (1999). Social dominance: An intergroup theory of social hierarchy and oppression. New York: Cambridge University Press.

Sidanius, J., Pratto, F., Martin, M., \& Stallworth, L. (1991). Consensual racism and career track: Some implications of social dominance theory. Political Psychology, 12, 691-721.

Sidanius, J., Pratto, F. \& Mitchell, M. (1994). Ingroup identification, social dominance orientation, and differential intergroup social allocation. Journal of Social Psychology, $134,151-167$.

Thernstrom, S., \& Thernstrom, A. (1997). America in Black and White: One nation, indivisible. New York: Simon and Shuster.

Thomsen, L., Green, E. G. T., \& Sidanius, J. (2008). We will hunt them down: How SDO and RWA fuels ethnic persecution of immigrants in fundamentally different ways. Journal of Experimental Social Psychology, 44, 1455-1464. 
Thomsen, L., Green, E. G. T., Ho, A. K., Sidanius, J., Levin, S., van Laar, C., \& Sinclair, S. (2010). Wolves in sheep's clothing: SDO asymmetrically predicts perceived ethnic victimization among White and Latino students across three years. Personality and Social Psychology Bulletin, 36, 225-238.

Tyler, T. R. (2006). Psychological perspectives on legitimacy and legitimation. Annual Review of Psychology, 57, 375-400.

Wing, N. (2010, November 9). Joyce Kaufman, Allen West’s Chief of Staff, advocated hanging illegal immigrants who commit crimes. The Huffington Post. Retrieved from http://www.huffingtonpost.com/2010/11/09/joyce-kaufman-allen-west-chief-ofstaff_n_781178.html

Wakslak, C., Jost, J., Tyler, T., \& Chen, E. (2007). Moral outrage mediates the dampening effect of system justification on support for redistributive social policies. Psychological Science, 18, 267-274.

Yoshimura \& Hardin (2009). Cognitive salience of subjugation and the ideological justification of U.S. geopolitical dominance in Japan. Social Justice Research, 22, 298-311. 


\section{Footnotes}

${ }^{1}$ Whereas a partial correlation examines the correlation between an independent variable (IV) and dependent variable (DV) after controlling for the effects of a third variable on both the IV and DV, a semi-partial, or part correlation examines the correlation between an IV and DV controlling for the effects of a third variable on the IV only.

${ }^{2}$ Based on the modification indices, we correlated the residuals of parcels 5 and 6 and parcels 5 and 1 in the two-factor model, and the residuals of parcels 5 and 6 and parcels 5 and 4 in the onefactor model.

${ }^{3}$ Based on the modification indices, we added one modification to the two models in Sample 4: We correlated the residuals of parcels 2 and 4 in the two-factor model, and the residuals of parcels 5 and 6 in the one-factor model.

${ }^{4}$ The $p$-values for the semi-partial correlations are based on significance tests of the B-coefficients produced in the regression analyses, which in principle provide the same information. 
Table 1.

Items Proposed to Form the SDO-D and SDO-E Dimensions (Jost \& Thompson, 2000)

\begin{tabular}{|c|c|}
\hline SDO - Dominance (SDO-D) & SDO - Egalitarianism (SDO-E) \\
\hline $\begin{array}{l}\text { 1. Some groups of people are just more worthy than } \\
\text { others } \\
\text { 2. In getting what your group wants, it is } \\
\text { sometimes necessary to use force against other } \\
\text { groups. } \\
\text { 3. Superior groups should dominate inferior groups } \\
\text { 4. To get ahead in life, it is sometimes necessary to } \\
\text { step on other groups. } \\
\text { 5. If certain groups of people stayed in their place, } \\
\text { we would have fewer problems. } \\
\text { 6. It's probably a good thing that certain groups are } \\
\text { at the top and other groups are at the bottom. } \\
\text { 7. Inferior groups should stay in their place. } \\
\text { 8. Sometimes other groups must be kept in their } \\
\text { place. }\end{array}$ & $\begin{array}{l}\text { 1. It would be good if all groups could be equal. } \\
\text { 2. Group equality should be our ideal. } \\
\text { 3. All groups should be given an equal chance in } \\
\text { life. } \\
\text { 4. We should do what we can to equalize } \\
\text { conditions for different groups. } \\
\text { 5. Increased social equality. } \\
\text { 6. We would have fewer problems if we treated } \\
\text { different groups more equally. } \\
\text { 7. We should strive to make incomes more equal. } \\
\text { 8. No one group should dominate in society. }\end{array}$ \\
\hline
\end{tabular}


Table 2.

Fit Statistics for Confirmatory Factor Analyses for Two- and One-Factor SDO Models and Chi-Square Difference Test Comparing the Two Models

\begin{tabular}{|l|l|l|l|l|}
\hline & $\chi^{2} / \mathrm{df}$ & RMSEA & CFI & $\chi^{2}$ difference test \\
\hline Sample 1 & & & & \\
\hline Two-factor model & 1.00 & 0.00 & 1.00 & $\chi^{2}$ diff $=35.15, \mathrm{df}=1, p<.001$ \\
\hline One-factor model & 5.88 & 0.17 & 0.95 & \\
\hline Sample 2 & & & & \\
\hline Two-factor model & 2.47 & 0.06 & 0.99 & $\chi^{2}$ diff $=479.94, \mathrm{df}=1, p<.001$ \\
\hline One-factor model & 55.52 & 0.34 & 0.78 & \\
\hline Sample 3 & & & & \\
\hline Two-factor model & 7.50 & 0.06 & 0.99 & $\chi^{2}$ diff $=1998.52, \mathrm{df}=1, p<.001$ \\
\hline One-factor model & 228.73 & 0.37 & 0.71 & \\
\hline Sample 4 & & & & \\
\hline Two-factor model & 1.13 & 0.03 & 1.00 & $\chi^{2}$ diff $=39.75, \mathrm{df}=1, p<.001$ \\
\hline One-factor model & 5.95 & 0.17 & 0.85 & \\
\hline Sample 5 & & & & \\
\hline Two-factor model & 0.58 & 0.00 & 1.00 & $\chi_{\text {diff }}^{2}=112.90, \mathrm{df}=1, p<.001$ \\
\hline One-factor model & 13.06 & 0.19 & 0.89 & \\
\hline
\end{tabular}


Table 3.

Semi-Partial (Part) Correlations Between SDO-E, SDO-D, and Criterion Variables Hypothesized to be Related to SDO-D

\begin{tabular}{|l|l|l|l|}
\hline Criterion Variable & SDO-E Part R & SDO-D Part R & Difference test \\
\hline Sample 1 - UCLA 1993 & & & \\
\hline Old racism & $.18^{* *}$ & $.33^{* * *}$ & $\mathrm{t}=-1.36, \mathrm{p}=.09$ \\
\hline Zero-sum competition & .09 & $.31^{* * *}$ & $\mathrm{t}=-1.84, \mathrm{p}=.04$ \\
\hline Nationalism & $.27^{* * *}$ & $.12+$ & $\mathrm{t}=1.25, \mathrm{p}=.11$ \\
\hline Sample 2 - Harvard 2007 & & & \\
\hline Old racism & $.18^{* * *}$ & $.37^{* * *}$ & $\mathrm{t}=-2.98, \mathrm{p}=.00$ \\
\hline Beliefs about immigrant persecution & .05 & $.42^{* * *}$ & $\mathrm{t}=-5.33, \mathrm{p}=.00$ \\
\hline Sample 3 - Harvard 2009 & & & \\
\hline Old racism & $.10^{* * *}$ & $.44^{* * *}$ & $\mathrm{t}=-9.67, \mathrm{p}=.00$ \\
\hline Beliefs about immigrant persecution & $.06^{* *}$ & $.46^{* * *}$ & $\mathrm{t}=-11.29, \mathrm{p}=.00$ \\
\hline Sample 4 - LACSS 1996 & & & \\
\hline Zero-sum competition & .07 & $.34^{* * *}$ & $\mathrm{t}=-2.36, \mathrm{p}=.00$ \\
\hline Sample 5 - Israeli universities 1994 & & & \\
\hline $\begin{array}{l}\text { Old-fashioned prejudice toward Mizrachi } \\
\text { Jews }\end{array}$ & $.15^{* *}$ & $.28^{* * *}$ & $\mathrm{t}=1.19, \mathrm{p}=.12$ \\
\hline Zero-sum competition (with Mizrachi Jews) & .02 & & \\
\hline Nationalism & $-.16^{*}$ & $.36^{* * *}$ & $\mathrm{t}=3.21, \mathrm{p}=.00$ \\
\hline Denial of Palestinian right to land & -.04 & $.44^{* * *}$ & $\mathrm{t}=3.25, \mathrm{p}=.00$ \\
\hline Jewish right over all of Israel & -.10 & $.39^{* * *}$ & $\mathrm{t}=4.45, \mathrm{p}=.00$ \\
\hline Giving Palestinian land threatens security & -.06 & $.36^{* * *}$ & $\mathrm{t}=3.74, \mathrm{p}=.00$ \\
\hline War support & -.06 & $.28^{* * *}$ & $\mathrm{t}=2.96, \mathrm{p}=.00$ \\
\hline Affect towards Palestinians & -.07 & $-.30^{* * *}$ & $\mathrm{t}=-2.11, \mathrm{p}=.02$ \\
\hline Right-wing political identification & .00 & $.32^{* * *}$ & $\mathrm{t}=2.73, \mathrm{p}=.00$ \\
\hline
\end{tabular}

Note. $+p<.10 ;{ }^{*} p<.05 ;{ }^{* *} p<.01 ;{ }^{* * *} p<.001$; difference tests are one-tailed. The $p$-values of the semi-partial correlations are based on significance tests of the B-coefficients obtained from the same regression analyses as the semi-partial correlations. 
Table 4

Semi-Partial (Part) Correlations Between SDO-E, SDO-D, and Criterion Variables Hypothesized to be Related to SDO-E

\begin{tabular}{|l|l|l|l|}
\hline Criterion Variable & SDO-E Part R & SDO-D Part R & Difference test \\
\hline Sample 1 - UCLA 1993 & & & \\
\hline Political conservatism & $.48^{* * *}$ & -.05 & $\mathrm{t}=4.80, \mathrm{p}=.00$ \\
\hline System legitimacy beliefs & $.45^{* * *}$ & -.02 & $\mathrm{t}=4.17, \mathrm{p}=.00$ \\
\hline Opposition to affirmative action & $.34^{* * *}$ & -.02 & $\mathrm{t}=2.90, \mathrm{p}=.00$ \\
\hline Protestant work ethic & $.39^{* * *}$ & -.03 & $\mathrm{t}=3.56, \mathrm{p}=.00$ \\
\hline Opposition to legally enforced racial policy & $.52^{* * *}$ & .06 & $\mathrm{t}=4.56, \mathrm{p}=.00$ \\
\hline Opposition to social welfare & $.46^{* * *}$ & .03 & $\mathrm{t}=3.96, \mathrm{p}=.00$ \\
\hline Sample 2 - Harvard 2007 & & & \\
\hline Political conservatism & $.30^{* * *}$ & $.11^{* *}$ & $\mathrm{t}=2.63, \mathrm{p}=.00$ \\
\hline System justification & $.36^{* * *}$ & $.15^{* * *}$ & $\mathrm{t}=3.12, \mathrm{p}=.00$ \\
\hline Opposition to affirmative action quotas & $.22^{* * *}$ & -.04 & $\mathrm{t}=3.36, \mathrm{p}=.00$ \\
\hline Opposition to redistributive social policy & $.47^{* * *}$ & $.12^{* *}$ & $\mathrm{t}=5.65, \mathrm{p}=.00$ \\
\hline Opposition to civil rights activist & $.27^{* * *}$ & $.19^{* * *}$ & $\mathrm{t}=1.21, \mathrm{p}=.11$ \\
\hline Belief that Harvard admissions is fair & $.40^{* * *}$ & $-.07+$ & $\mathrm{t}=6.51, \mathrm{p}=.00$ \\
\hline Sample 3 - Harvard 2009 & & & \\
\hline Political conservatism & $.37^{* * *}$ & $.04+$ & $\mathrm{t}=8.86, \mathrm{p}=.00$ \\
\hline Opposition to redistributive social policy & $.55^{* * *}$ & $.04+$ & $\mathrm{t}=15.88, \mathrm{p}=.00$ \\
\hline Opposition to civil rights activist & $.34^{* * *}$ & $.13^{* * *}$ & $\mathrm{t}=5.63, \mathrm{p}=.00$ \\
\hline Belief that Harvard admissions is fair & $.31^{* * *}$ & $-.05^{*}$ & $\mathrm{t}=8.90, \mathrm{p}=.00$ \\
\hline Sample 4 - LACSS 1996 & & & \\
\hline Political conservatism & $.28^{* * *}$ & .07 & $\mathrm{t}=1.73, \mathrm{p}=.04$ \\
\hline Affirmative action opposition & $.31^{* * *}$ & .03 & $\mathrm{t}=2.33, \mathrm{p}=.01$ \\
\hline Protestant work ethic & $.22^{* *}$ & .09 & $\mathrm{t}=1.11, \mathrm{p}=.14$ \\
\hline Symbolic racism & $.29^{* * *}$ & $.14+$ & $\mathrm{t}=1.29, \mathrm{p}=.10$ \\
\hline Sample 5 - Israeli universities 1994 & $.24^{* * *}$ & $.25^{* * *}$ & $\mathrm{t}=-.09, \mathrm{p}=.41$ \\
\hline System justification & $.39^{* * *}$ & $-.14^{*}$ & $\mathrm{t}=-4.77, \mathrm{p}=.00$ \\
\hline Opposition to income redistribution & $.22^{* * *}$ & $-.11+$ & $\mathrm{t}=.83, \mathrm{p}=.20$ \\
\hline Affect towards Mizrachi Jews & & $-.17^{*}$ & $\mathrm{t}=-3.38 \mathrm{p}=.00$ \\
\hline Equal opportunity & & \\
\hline
\end{tabular}

Note. $+p<.10 ;{ }^{*} p<.05 ;{ }^{* *} p<.01 ;{ }^{* * *} p<.001$; difference tests are one-tailed. The $p$-values of the semi-partial correlations are based on significance tests of the B-coefficients obtained from the same regression analyses as the semi-partial correlations. 


\section{$\underline{\text { Appendix } 1}$}

All measures used a 1 (Strongly disagree/disapprove) to 7 (Strongly agree/approve) scale unless otherwise indicated.

\section{Sample 1}

$\underline{\text { SDO-D Criterion Variables }}$

Old-fashioned racism $(\alpha=.89)$

1. Blacks are inherently inferior.

2. Chicanos/Latinos are inherently inferior.

3. African Americans are less intellectually able than other groups.

4. African Americans are lazier than other groups.

5. Latinos are less intellectually able than other groups.

6. Latinos are lazier than other groups.

Zero-sum competition $(\alpha=.67)$

1. Better jobs for African Americans means fewer good jobs for Whites.

2. The economic advancement of certain groups threatens the advancement of other ethnic groups.

Nationalism $(\alpha=.60)$

1. For the most part, America is no more superior than any other industrialized country in the world.

2. To maintain our country's economic superiority, aggressive economic policies are sometimes necessary.

3. The USA should not dominate other countries.

4. There are many other cultures in the world that are superior to ours.

\section{$\underline{\text { SDO-E Criterion Variables }}$}

Political conservatism $(\alpha=.88)$

1. How would you describe your political party preference? 1 = "Strong Democrat" to 7 = "Strong Republican"

2. In terms of economic issues, how would you describe your political attitudes and beliefs? 1 = "Very liberal" to 7 = "Very conservative"

3. In terms of social issues, how would you describe your political attitudes and beliefs? 1 = "Very liberal" to 7 = "Very conservative"

System legitimacy beliefs $(\alpha=.78)$

1. America is a just society where differences in status between ethnic groups reflect actual group differences. 
2. Differences in status between ethnic groups are fair.

3. Minority groups are given the same treatment as other ethnic groups in the criminal justice system.

4. American society treats all ethnic groups equally.

5. Although there was discrimination in the past, today members of all ethnic groups have equal opportunity.

Opposition to affirmative action ( $\alpha=\mathrm{N} / \mathrm{A})$

1. Affirmative action.

Protestant work ethic $(\alpha=.81)$

1. America is a just society where differences in status between ethnic groups reflect actual group differences.

2. If people work hard they almost always get what they want.

3. Most people who don't get ahead should not blame the system; they really have only themselves to blame.

4. In America, getting ahead doesn't always depend on hard work.

5. Even if people work hard, they don't always get ahead.

Opposition to legally enforced racial policy $(\alpha=.87)$

1. Government should see to it that minorities get fair treatment in jobs.

2. Government should not pass laws concerning the hiring of ethnic minorities.

3. Government should ensure that Whites and minorities go to the same school

4. Government has no business trying to ensure racial integration in schools

5. Government should do what it can to improve the economic condition of poor ethnic minorities.

6. Government has no business trying to improve the economic condition of poor ethnic minorities.

Opposition to social welfare $(\alpha=.83)$

1. Greater assistance to the poor

2. Reduced public support for the homeless

3. Reduced benefits for the unemployed

\section{Sample 2}

$\underline{\text { SDO-D Criterion Variables }}$

Old-fashioned racism $(\alpha=.75)$

1. Racial integration

2. White superiority

3. Blacks are inherently inferior

Willingness to participate in immigrant persecution $(\alpha=.93)$ 
Now, suppose that the American government some time in the future passed a law outlawing immigrant organizations in the US. Government officials then stated that the law would only be effective if it were vigorously enforced at the local level and appealed to every American to aid in the fight against these organizations.

Please indicate how much you agree or disagree with the following statements:

1. I would tell my friends and neighbors that it was a good law.

2. I would tell the police about any immigrant organizations that I knew.

3. If asked by the police, I would help hunt down and arrest members of immigrant organizations.

4. I would participate in attacks on the immigrant headquarters organized by the proper authorities.

5. I would support physical force to make member of immigrant organizations reveal the identity of other members.

6. I would support the execution of leaders of immigrant organizations if the government insisted it was necessary to protect the United States.

\section{$\underline{\text { SDO-E Criterion Variables }}$}

Political conservatism $(\alpha=.81)$

1. How would you describe your political party preference?

$\begin{array}{lll}\text { Strong Republican } & \text { Weak Republican } & \text { Independent Republican } \\ \text { Independent } & \text { Independent Democrat } & \text { Weak Democrat }\end{array}$

2. In terms of economic issues, how would you describe your political attitudes and beliefs?

$\begin{array}{ll}\text { Very Conservative } & \text { Conservative } \\ \text { Middle-of-the-road } & \text { Slightly Liberal } \\ \text { Very Liberal } & \end{array}$

3. In terms of social issues, how would you describe your political attitude and beliefs?

$\begin{array}{lll}\text { Very Conservative } & \text { Conservative } & \text { Slightly Conservative } \\ \text { Middle-of-the-road } & \text { Slightly Liberal } & \text { Liberal }\end{array}$

Other (please specify)

System justification $(\alpha=.68)$

Please use the following scale to rate the extent to which each of the following statements is true for you. There are no right or wrong answers for any question. The best answer is what you think is true for yourself.

1. Our society is an open society where all individuals can achieve higher status.

2. Advancement in our society is possible for all individuals.

3. Differences in status between groups in society are fair. 
4. Differences in status between groups in society are the result of injustice.

Affirmative action quotas ( $\alpha=\mathrm{N} / \mathrm{A})$

Please indicate how you personally feel about different kinds of affirmative action. For the following policy, please indicate if you strongly support, somewhat support, somewhat oppose, or strongly oppose the policy.

1. Quotas, that is, setting aside places for certain groups.

1 = strongly oppose, 2 = somewhat oppose, 3 = somewhat support, $4=$ strongly support

Opposition to redistributive social policy $(\alpha=.73)$

1. Government sponsored healthcare for everybody

2. Low income housing

3. Reduced benefits for the unemployed

4. Increased taxation of the rich

Civil rights activist $(\alpha=\mathrm{N} / \mathrm{A})$

1. Civil-rights activists

Harvard admissions fair $(\alpha=.85)$

1. Societal injustice makes it impossible for some Blacks to get the acceptance to Harvard that they truly deserve.

2. Societal injustice makes some Whites get an acceptance to Harvard that they don't actually deserve.

3. Societal injustice makes some White persons get the spot at Harvard that should have been given to another, Black, person if things were fair.

\section{Sample 3}

$\underline{\text { SDO-D Criterion Variables }}$

Old-fashioned racism $(\alpha=.75)$

1. Racial integration

2. White superiority

3. Blacks are inherently inferior

Beliefs about immigrant persecution $(\alpha=.91)$

Now, suppose that the American government some time in the future passed a law outlawing immigrant organizations in the US. Government officials then stated that the law would only be effective if it were vigorously enforced at the local level and appealed to every American to aid in the fight against these organizations.

Please indicate how much you agree or disagree with the following statements: 
1. I would tell my friends and neighbors that it was a good law.

2. I would tell the police about any immigrant organizations that I knew.

3. If asked by the police, I would help hunt down and arrest members of immigrant organizations.

4. I would participate in attacks on the immigrant headquarters organized by the proper authorities.

5. I would support physical force to make member of immigrant organizations reveal the identity of other members.

6. I would support the execution of leaders of immigrant organizations if the government insisted it was necessary to protect the United States.

\section{SDO-E Criterion Variables}

Political conservatism $(\alpha=.89)$

1) How would you describe your political party preference?

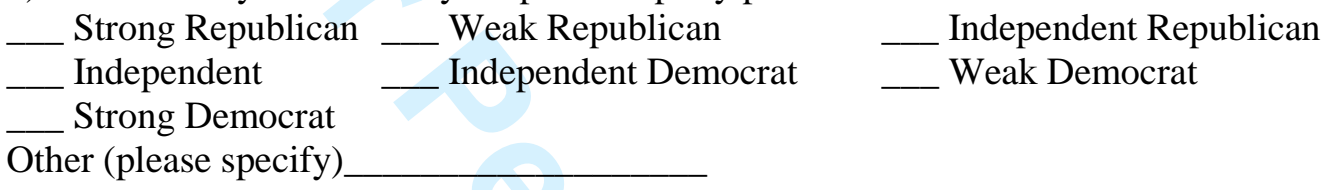

2) In terms of economic issues, how would you describe your political attitudes and beliefs?

$\begin{array}{lll}\text { Very Conservative } & \text { Conservative } & \text { Slightly Conservative } \\ \text { Middle-of-the-road } & \text { Slightly Liberal } & \text { Liberal }\end{array}$

Other (please specify)

3) In terms of social issues, how would you describe your political attitude and beliefs? Very Conservative Conservative Middle-of-the-road Slightly Liberal Slightly Conservative Very Liberal
Other (please specify)

Opposition to redistributive social policy $(\alpha=.73)$

1. Government sponsored healthcare for everybody

2. Low income housing

3. Reduced benefits for the unemployed

4. Increased taxation of the rich

Civil rights activist $(\alpha=\mathrm{N} / \mathrm{A})$

1. Civil-rights activists

Harvard admissions fair $(\alpha=.88)$

1. Societal injustice makes it impossible for some Blacks to get the acceptance to Harvard that they truly deserve. 
2. Societal injustice makes some Whites get an acceptance to Harvard that they don't actually deserve.

3. Societal injustice makes some White persons get the spot at Harvard that should have been given to another, Black, person if things were fair.

\section{Sample 4}

$\underline{\text { SDO-D Criterion Variables }}$

Zero-sum competition $(\alpha=.77)$

Do you strongly agree, somewhat agree, somewhat disagree, or strongly disagree with the statement?

1. More good jobs for Blacks means fewer good jobs for members of other groups.

2. The more influence Blacks have in local politics the less influence members of other groups will have in local politics.

3. The more good housing and neighborhoods go to Blacks, the fewer good houses and neighborhoods there will be for members of other groups.

4. Many Blacks have been trying to get ahead economically at the expense of members of other groups.

\section{$\underline{\text { SDO-E Criterion Variables }}$}

Political conservatism $(\alpha=.67)$

1. Generally speaking, and regardless of how you are registered, do you usually think of yourself as a democrat, a republican, neither a democrat nor a republican, an independent, or what?

a. Do you think of yourself as a strong or not so strong ___ ?

2. Would you describe your political views in general as very conservative, somewhat conservative, neither conservative nor liberal, somewhat liberal, or very liberal?

Do you strongly agree, somewhat agree, somewhat disagree, or strongly disagree with the statement?

3. The government should guarantee that basic health care is available for all Americans.

4. The government should lower taxes.

5. The government has taken over too many things that should be handled by individuals, families, and private businesses.

Affirmative action opposition ( $\alpha=\mathrm{N} / \mathrm{A})$

Please tell me if you strongly support, somewhat support, somewhat oppose, strongly oppose, or have you never heard of affirmative action?

1. In general, do you support or oppose affirmative action?

1 = strongly support to 4 = strongly oppose 
Protestant work ethic $(\alpha=.70)$

Please tell me whether you strongly agree, somewhat agree, somewhat disagree, or strongly disagree with these statements:

1. Although there was discrimination in the past, today members of all groups have an equal opportunity to succeed.

2. Success, or one's achievement, in American society depends primarily on individual merit.

Symbolic racism $(\alpha=.67)$

Please tell me if you strongly agree, somewhat agree, somewhat disagree, or strongly disagree with the following statements:

1. If blacks work hard they almost always get what they want.

2. Hard work offers little guarantee of success for blacks.

3. Blacks are getting too demanding in their push for equal rights.

4. The Irish, Italians, Jews and many other minorities overcame prejudice and worked their way up. Blacks should do the same without any special favors.

\section{Sample 5}

\section{$\underline{\text { SDO-D Criterion Variables }}$}

Old-fashioned prejudice toward Mizrachi Jews $(\alpha=.58)$

On average, Mizrachim have lower income and less political power than Ashkenazim. Several explanations have been suggested for this. Using the scale below, indicate the degree to which you agree or disagree with each of these explanations:

1. Mizrachim are less intellectually able than Ashkenazim.

2. Mizrachim have lower motivation to succeed than Ashkenazim.

$$
\begin{array}{llllllllll}
\text { Do not agree at all } & 1 & 2 & 3 & 4 & 5 & 6 & 7 & \text { Strongly agree }
\end{array}
$$

\section{Zero-sum competition with Mizrachi Jews $(\alpha=.70)$}

Below are a series of statements with which you may either agree or disagree. For each statement, please indicate the degree of your agreement or disagreement by circling the appropriate number from ' 1 ' to ' 7 '. Please remember that there are no right or wrong answers, and that your first responses are usually the most accurate.

1. Better jobs for Mizrachim means fewer good jobs for Ashkenazim.

2. The economic advancement of the Mizrachim threatens the advancement of the Ashkenazim.

$$
\begin{array}{lllllllll}
\text { Do not agree at all } & 1 & 2 & 3 & 4 & 5 & 6 & 7 & \text { Strongly agree }
\end{array}
$$


Nationalism $(\alpha=.47)$

1. Since Israel is far from perfect, the country has many things to learn from other countries.

2. For the most part, Israel is no more superior than any other industrialized country in the world.

3. For me, there is no culture in the world that is superior to ours.

\section{Denial of Palestinian right to land $(\alpha=.89)$}

1. What are you willing to give up in the West Bank in order to reach a peace agreement with the Palestinians?

1. Everything

2. The majority

3. A certain part

4. A small part

5. Nothing at all

Different solutions have been put forth for the future of the territories so that Israel will achieve peace and security. To what extent do you support or oppose each of the following solutions:

2. Do you support or oppose Israel's forcing the Arabs to leave the territories in exchange for compensation, as stated by the transfer plan?

3. Do you support or oppose annexation of the territories without giving equal rights to the Palestinians?

4. Do you support or oppose the establishment of a Palestinian state?

$$
\begin{array}{llllllllll}
\text { Strongly oppose } & 1 & 2 & 3 & 4 & 5 & 6 & 7 & \text { Strongly support }
\end{array}
$$

Jewish right over all of Israel $(\alpha=.77)$

1. I believe in the right of the Jewish people over all the Land of Israel.

2. The Palestinians have no right to demand territories from the Land of Israel.

Giving Palestinian land threatens security $(\alpha=.92)$

1. Giving land to the Palestinians threatens the security of Israel.

2. The Palestinians have no right to demand territories from the Land of Israel.

3. A Palestinian state threatens the security of Israel.

War support $(\alpha=\mathrm{N} / \mathrm{A})$

1. To maintain Israel's superiority, war is sometimes necessary.

Affect toward Palestinians $(\alpha=N / A)$

Using the scales provided, please indicate how positively or negatively you feel towards the following groups: 
1. Palestinians

\author{
$\begin{array}{llllllllll}\text { Very Negatively } & 1 & 2 & 3 & 4 & 5 & 6 & 7 & \text { Very Positively }\end{array}$ \\ Right-wing political identification $(\alpha=\mathrm{N} / \mathrm{A})$
}

On the following scale, '7' represents identification with the political right and 'I'

represents identification with the political left. Where do place yourself on this scale?

$$
\begin{array}{lllllllll}
\text { Left } & 1 & 2 & 3 & 4 & 5 & 6 & 7 & \text { Right }
\end{array}
$$

\title{
$\underline{\text { SDO-E Criterion Variables }}$
}

System justification $(\alpha=.56)$

1. Israel is a just society where differences in status between ethnic groups reflect actual group differences.

2. Differences in status between ethnic groups are fair.

3. Differences in status between ethnic groups are the result of injustice.

Opposition to income redistribution $(\alpha=.51)$

Below are a series of statements with which you may either agree or disagree. For each statement, please indicate the degree of your agreement or disagreement by circling the appropriate number from ' 1 ' to ' 7 '. Please remember that there are no right or wrong answers, and that your first responses are usually the most accurate.

1. We must give greater assistance to the poor.

2. We must increase taxation of the rich.

$$
\begin{array}{llllllllll}
\text { Do not agree at all } & 1 & 2 & 3 & 4 & 5 & 6 & 7 & \text { Strongly agree }
\end{array}
$$

Affect toward Mizrachi Jews ( $\alpha=\mathrm{N} / \mathrm{A})$

Using the scales provided, please indicate how positively or negatively you feel towards the following groups:

\section{Mizrachim}

$$
\begin{array}{llllllllll}
\text { Very Negatively } & 1 & 2 & 3 & 4 & 5 & 6 & 7 & \text { Very Positively }
\end{array}
$$

Equal opportunity $(\alpha=.82)$

1. Israel is an open society where individuals of any ethnicity can achieve higher status.

2. Advancement in Israeli society is possible for individuals of all ethnic groups.

3. Individual members of a low status ethnic groups find it difficult to achieve higher status.

4. Mizrachim usually don't get fair treatment (in the labor market, education, and politics). 
5. Ashkenazim and Mizrachim have the same chances of finding jobs that match their skills.

6. Ashkenazim and Mizrachim with the same qualifications have the same chances of getting into college.

7. People often discriminate against Mizrachim.

8. Although there was discrimination in the past, today members of all ethnic groups have equal opportunities. 